\title{
Tim-3 expression on peripheral T cell subsets correlates with disease progression in hepatitis B infection
}

\author{
Wei $\mathrm{Wu}^{\dagger}$, Yu Shi ${ }^{\dagger}$, Jie Li, Feng Chen, Zhi Chen, Min Zheng ${ }^{*}$
}

\begin{abstract}
Background and objective: T-cell immunoglobulin domain and mucin domain-containing molecule-3 (Tim-3) represents a novel mechanism of T-cell dysfunction in chronic viral diseases. However, the role of Tim-3 in the pathogenesis of chronic hepatitis B (CHB) is not well understood. We investigated Tim-3 expression on peripheral T cell subsets and analyzed the relationship between Tim-3 expression and disease progression in HBV infection.

Methods: peripheral blood samples were obtained from CHB patients $(n=40)$, including 23 patients with moderate $\mathrm{CHB}[\mathrm{MCHB}]$ and 17 with severe $\mathrm{CHB}[\mathrm{SCHB}]$. Control samples were obtained from nine acute hepatitis $\mathrm{B}$ patients (AHB) and 26 age-matched healthy subjects. The expression of Tim-3 on T cells was determined by flow cytometry.

Results: Tim-3 expression was elevated on peripheral $\mathrm{CD}^{+}$and $\mathrm{CD} 8^{+} \mathrm{T}$ cells from $\mathrm{AHB}$ and $\mathrm{CHB}$ patients compared to those from healthy controls. The percentage of Tim- $3^{+} \mathrm{T}$ cells was further increased in SCHB patients relative to $\mathrm{MCHB}$ patients and showed a positive correlation with conventional markers for liver injury (alanine aminotransferase (ALT), aspartate transaminase (AST), total bilirubin (TB) and international normalized ratio (INR) level). The frequency of Tim-3-expressing T cells was negatively correlated with T-bet mRNA expression and plasma interferon-gamma (INF-gamma) levels. Further, Tim-3 expression on $\mathrm{CD}^{+}$or $\mathrm{CD}^{+} \mathrm{T}$ cells was reduced in $\mathrm{CHB}$ patients with disease remission after antiviral treatment and in AHB patients during the convalescence phase.

Conclusions: Our results suggest that over-expression of Tim-3 is involved in disease progression of CHB and that Tim-3 may participate in skewing of Th1/Tc1 response, which contributes to persistency of HBV infection.
\end{abstract}

\section{Introduction}

Chronic hepatitis B virus (HBV) infection is a global health burden with 350-400 million people infected worldwide. Approximately 1 million deaths occur annually due to the long-term complications of infection including cirrhosis, liver failure and hepatocellular carcinoma [1]. Adaptive Tcell immunity plays a pivotal role in viral clearance [2]. Patients chronically infected with HBV present impaired T helper 1 cells (Th1) response and consequently impaired cytotoxic T lymphocyte (Tc1) priming, which results in viral persistence and liver damage [3]. In contrast those who recovered from acute HBV infection (AHB) exhibit

\footnotetext{
* Correspondence: minzheng@zju.edu.cn

† Contributed equally

State Key Laboratory for Diagnosis and Treatment of Infectious Diseases, First Affiliated Hospital, School of Medicine, Zhejiang University, Hangzhou 310006, China
}

\section{Biomed Central}

normal Th1 and Tc1 function. The cause(s) of T-cell dysfunction in chronically infected patients have not been fully clarified.

Recent studies have focused on the role of membrane inhibitory receptors in modulating $\mathrm{T}$-cell dysfunction during chronic viral diseases. Programmed cell death-1 (PD-1), a member of the CD28 family, was found to be up-regulated on the surfaces of exhausted $\mathrm{T}$ cells during chronic lymphocytic choriomeningitis virus (LCMV) [4], human immunodeficiency virus (HIV) [5], hepatitis C virus (HCV) [6] and HBV infections [7]. Furthermore, blockade of this pathway ex vivo or in vivo significantly improved T-cell function. However, T-cell exhaustion was not always completely corrected by blocking the PD-1 pathway, suggesting that other pathways may involved in T-cell dysfunction [8]. 
T-cell immunoglobulin domain and mucin domaincontaining molecule-3 (Tim-3) was first found to be expressed on Th1 but not Th2 cells [9]. Tim-3 negatively regulates $\mathrm{Th} 1$ response and induces tolerance through the Tim-3/Galectin-9 pathway in autoimmune diseases [10]. Tim-3 is highly expressed on effector $\mathrm{T}$ cells during HIV and HCV infection, and blocking the Tim-3 signaling pathway restores proliferation and enhanced cytokine production of effector $\mathrm{T}$ cells $[11,12]$. Furthermore, a synergistic effect was observed by blocking both the Tim-3 and PD-1 pathway during chronic LCMV infection [13]. Taken together, these results indicated that Tim-3 might be another negative regulatory receptor contributing to $\mathrm{T}$-cell dysfunction.

However, the role of Tim-3 in HBV infection has not been clarified. Therefore we investigated the expression of Tim-3 on peripheral $\mathrm{T}$ cells in patients chronically infected with hepatitis B and tested whether the expression level of Tim-3 correlates with disease progression.

\section{Materials and methods \\ Subjects}

Samples were obtained from HBV-infected patients admitted to the infectious department of our hospital, including with 23 with mild $\mathrm{CHB}$ (MCHB), 17 with severe $\mathrm{CHB}$ (SCHB), 9 with AHB and 26 healthy controls. The demographic features of study group are presented in Table 1. The mean age of SCHB patients was higher than that of the other three groups. There was no significant difference in sex proportion among the groups.

The criteria for diagnosis of $\mathrm{AHB}$ and $\mathrm{CHB}$ were described in detail previously [14]. SCHB was diagnosed if serum total bilirubin (TBIL) [15] exceed 10 times of normal upper limit (171 uM) and prothrombin time activity (PTA) exceed 40\%, while those with TBIL less than $171 \mathrm{uM}$ and PTA less than $40 \%$ were diagnosed as MCHB. We excluded individuals co-infected with hepatitis $\mathrm{C}$ virus (HCV), hepatitis D virus (HDV) and human immunodeficiency virus (HIV); persons with other causes of chronic liver diseases such as autoimmune hepatitis and Wilson disease; patients with suspected signs of hepatocellular carcinoma $(\mathrm{HCC})$ by ultrasound or serum AFP; and anyone who received antiviral treatment within the previous 6 months. This study was approved by the local ethics committee and we obtained written informed consent from each study participant. The study was carried out in accordance with Declaration of Helsinki.

\section{Virological assessment}

Serological markers of HBV, HCV, HDV and HIV were tested by commercial enzyme immunoassay kits (AXSYM System, Abbott, Wiesbaden, Germany) as previously described [16]. Serum HBV DNA level was determined using a quantitative polymerase chain reaction (qPCR) assay (PG Biotech, Shenzhen, China). The lower detection limit threshold is 500 copies $/ \mathrm{ml}$.

\section{PBMC isolation}

Peripheral blood mononuclear cells (PBMCs) were isolated from fresh-heparinized blood by standard Ficoll-Hypaque density centrifugation (Biochrom, Berline, Germany). PBMC isolation was performed no more than 2 hours after peripheral blood was collected by venipuncture.

\section{Flow cytometric analysis}

For Tim-3 expression analysis, freshly-isolated PBMCs were stained with anti-CD3-APC, anti-CD4-FITC or anti-CD8-FITC (BD Biosciences) and anti-TIM-3-PE

Table 1 Clinical characteristics of the studied groups

\begin{tabular}{lllll}
\hline Variables & N.C. $(\mathbf{N}=\mathbf{2 6})$ & AHB $(\mathbf{N}=\mathbf{9})$ & MCHB (N = 23) & SCHB (N = 17) \\
\hline Age (year) & $30.2 \pm 5.4$ & $32.7 \pm 13.5$ & $33.1 \pm 11.4$ & $42.8 \pm 13.1$ \\
Sex & 69.2 & 88.9 & 70.0 & 70.6 \\
HBsAg (\%) & 0 & 77.8 & 100 & 100 \\
HBsAb (\%) & 21.5 & 77.8 & 0 & 0 \\
HBeAg (\%) & 0 & 22.2 & 50 & 35.7 \\
HBeAb (\%) & 3.8 & 100 & 50 & 71.4 \\
HBcAb (\%) & 34.6 & $4.66 \pm 2.95$ & 100 & 100 \\
Log HBV DNA & NA & $1197.5 \pm 804.7$ & $6.87 \pm 1.59$ & $4.34 \pm 3.07$ \\
ALT (IU/L) & $15.3 \pm 9.2$ & $537.1 \pm 539.0$ & $360.6 \pm 344.6$ & $487.8 \pm 775.9$ \\
AST (IU/L) & $11.7 \pm 6.8$ & $113.2 \pm 105.6$ & $241.7 \pm 261.3$ & $417.2 \pm 597.1$ \\
Bilirubin (umol/L) & $14 \pm 11.1$ & $1.14 \pm 0.26$ & $65.6 \pm 55.2$ & $332.5 \pm 179.6$ \\
INR & NA & $1.02 \pm 0.12$ & $2.32 \pm 0.85$
\end{tabular}

Data were expressed as mean \pm SD or percentage; N.C.: normal control; AHB: acute hepatitis B; MCHB: moderate chronic hepatitis B; SCHB: severe chronic hepatitis B; ALT: alanine aminotransferase; AST: aspartate transaminase; INR: international normalized ratio. 
(R\&D Systems). To exclude nonspecific binding, isotypematched antibodies (Beckman Coulter) were used as controls. At least $1 \times 10^{5}$ cells were analyzed using a Beckman Coulter flow cytometer (FC500 MPL, Fullerton, CA, USA).

\section{Quantification of T-bet mRNA by real-time PCR}

Total RNA was extracted from freshly isolated PBMCs according to the manufacturer's protocol (Invitrogen, Carlsbad, CA). The T-bet mRNA was determined by performing a real-time PCR with SYBR-green I Premix ExTaq on the ABI Prism 7900 (Applied Bio systems, Foster, CA). The primer pairs were used as follow: T-bet-forward: TGTGACCCAGATGATTGTGC; T-bet-reverse: AAAGATATGCGTGTTGGAAGC; GAPDH-forward: GGTGGTCTCCTCTGACTTCAACA; GAPDH-reverse: GTTGCTGTAGCCAAATTCGTTGT. All PCR assays were performed in duplicate, and data were analyzed with the ABI Prism Detection system using the comparative threshold cycle method as previously described.
GAPDH was used as internal control and RNA samples from the healthy groups were used as quality control in each RT-PCR.

\section{Quantification of plasma INF-gamma by flow-cytomix}

Plasma INF-gamma level was determined using the flow-cytomix simplex kit, according to the manufacturer's instructions (Bender MedSystem, Copenhagen, Denmark). The detection thresholds were $1.6 \mathrm{pg} / \mathrm{ml}$.

\section{Statistical analysis}

Data were expressed as mean \pm SD or number (\%). The Mann-Whitney U test and Chi-Square test were used to compare differences among the study groups. The paired $t$ test was used to compare differences in Tim-3 expression before and after treatment, at early phase, and at convalescence stage. Spearman correlation was conducted to assess the association between the frequency of Tim-3-expressing $T$ cells and the other indicated parameters. A $\mathrm{P}$ value of less than 0.05 was
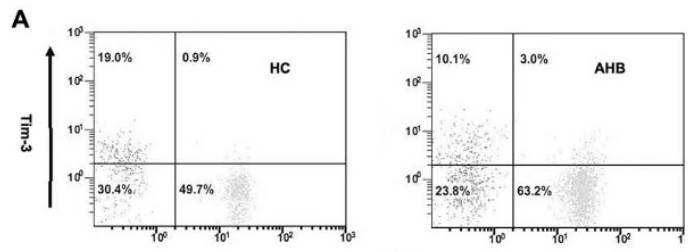

$\operatorname{CD} 4$
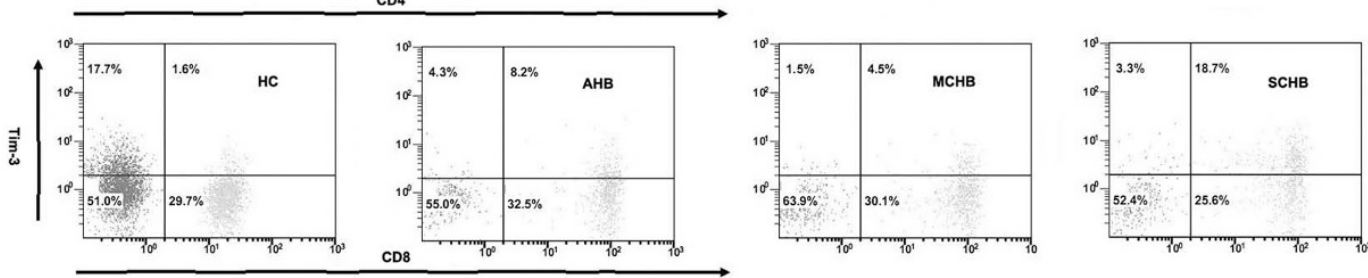

B
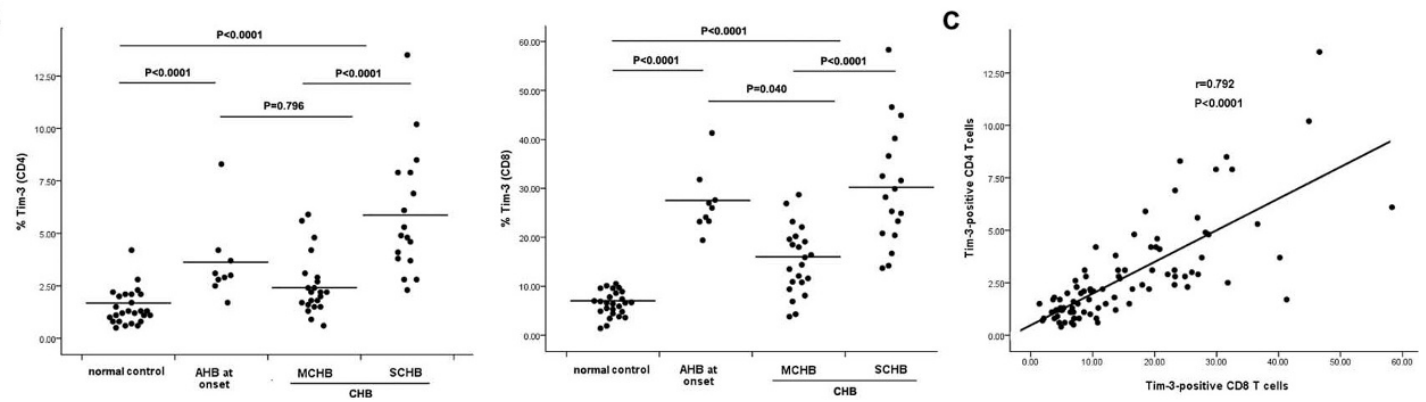

Figure 1 Elevated Tim-3 expression on circulating CD4 and CD8 T cells in HBV-infected individuals. (A) PBMCs from normal controls, AHB patients (early phase), MCHB and SCHB patients were stained with antibodies against CD3, CD4/CD8, and Tim-3. An isotype-matched antibody was used as a negative control. (B) The percentage of Tim-3 cells within CD4+ and CD8+ T cell populations are increased in AHB and CHB patients and further enhanced in the severe stage of $\mathrm{CHB}$. Each dot represents an individual data point and the horizontal lines represent the mean. The Mann-Whitney $U$ test was used to compare differences among groups. (C) There is a significantly positive correlation between the frequency of Tim-3-expressing $C D 4^{+}$and $C D 8^{+} T$ cells in the studied subjects. Spearman test was performed for correlation analysis. 
considered to be statistically significant. All statistical analysis was performed with SPSS 16.0 for Windows (SPSS, Chicago, IL).

\section{Results}

2.1 Up-regulation of Tim-3 expression on peripheral T-cell subsets in HBV-infected subjects

We examined Tim-3 expression from patients in the three groups by flow cytometry on PBMCs using an anti-Tim-3 polyclonal antibody. An elevated frequency of Tim-3-positive CD4 $4^{+}$cells was observed in subjects with $\mathrm{AHB}$ (onset) and $\mathrm{CHB}$ compared to non-infected controls $(1.48 \pm 0.83 \%$ for normal controls versus $3.58 \pm$
$1.90 \%$ for patients with AHB [P < 0.0001], $3.93 \pm 2.76 \%$ for $\mathrm{CHB}$ patients $[\mathrm{P}<0.0001]$, Figure $1 \mathrm{~A}$ and $1 \mathrm{~B})$. We also observed increased Tim- 3 expression on $\mathrm{CD} 8^{+} \mathrm{T}$ cells from $\mathrm{AHB}$ and $\mathrm{CHB}$ patients, relative to normal controls $(6.43 \pm 2.50 \%$ for controls versus $27.12 \pm 6.33 \%$ for AHB patients $[\mathrm{P}<0.0001]$ and $21.34 \pm 11.95 \%$ for $\mathrm{CHB}$ patients, Figure $1 \mathrm{~A}$ and $1 \mathrm{~B})$. Patients with $\mathrm{AHB}$ presented higher Tim-3 expression on $\mathrm{CD}^{+}(\mathrm{P}=0.040)$ but not $\mathrm{CD}^{+} \mathrm{T}$ cells $(\mathrm{P}=0.796)$ relative to $\mathrm{CHB}$ patients. Tim-3 expression on both $\mathrm{CD} 4^{+}(\mathrm{P}<0.0001)$ and $\mathrm{CD}^{+}(\mathrm{P}<0.0001) \mathrm{T}$ cells was significantly elevated in SCHB patients compared to that in MCHB patients. Furthermore, the frequency of Tim-3-expressing CD $4^{+}$
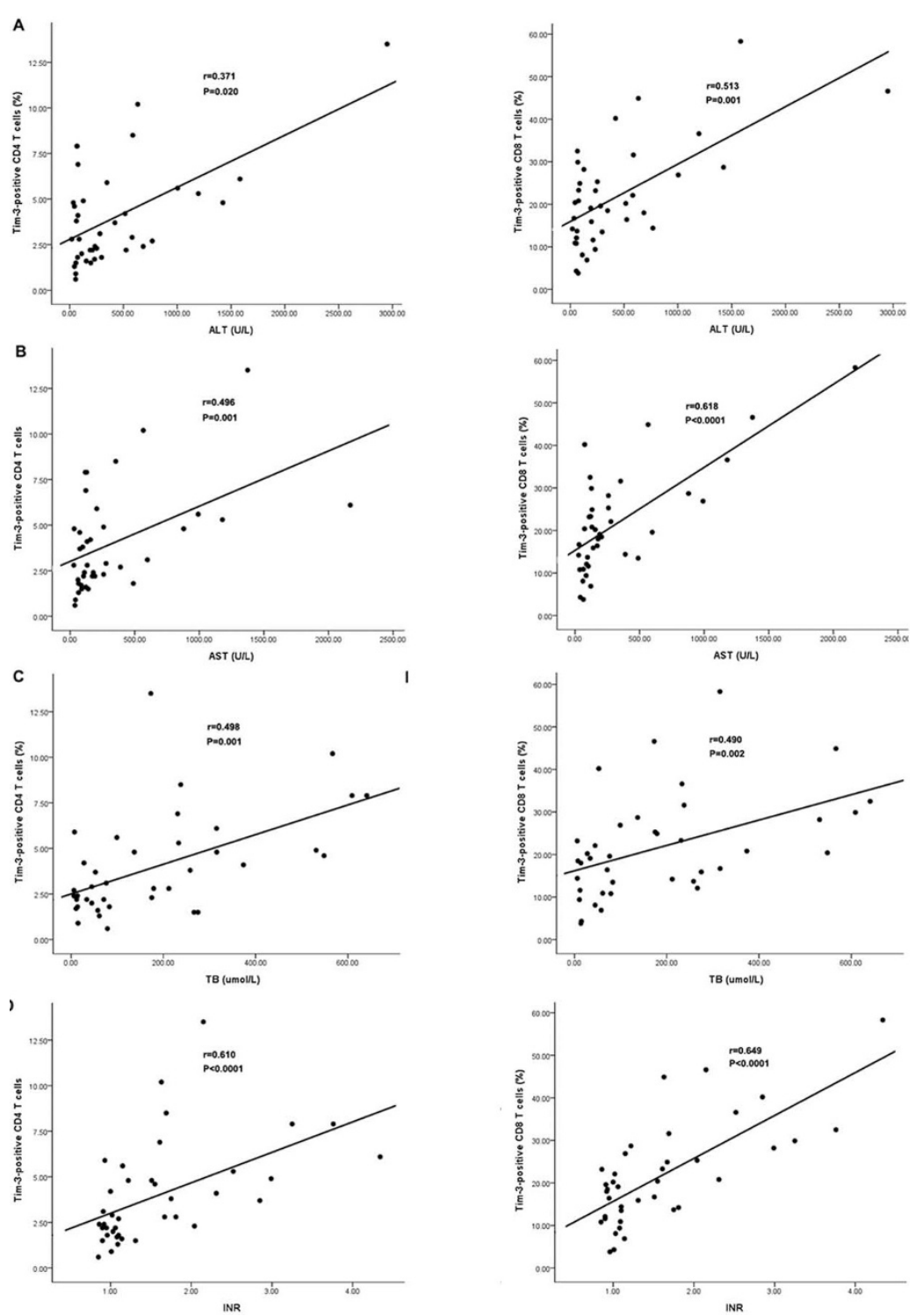

Figure 2 Association between the frequency of $\mathrm{Tim}^{-3^{+}} \mathrm{T}$ cells and conventional markers for liver damage in $\mathrm{CHB}$ patients. The frequency of $\mathrm{CD}^{+}$or $\mathrm{CD}^{+} \mathrm{T}$ cells expressing Tim-3 are positively correlated with the levels of laboratory parameters for assessing liver injury such as ALT (A), AST (B), TB (C) and INR (D). Spearman test was used for correlation analysis. 
T cells correlated significantly with Tim-3 expression on $\mathrm{CD}^{+} \mathrm{T}$ cells $(\mathrm{r}=0.792, \mathrm{P}<0.0001$, Figure $1 \mathrm{C})$. Taken together these results indicate that Tim-3 expression is increased in parallel with disease severity.

\subsection{The frequency of Tim-3-expressing T cells correlates with hepatic injury but not viral load in CHB patients}

We then evaluated the correlation between Tim-3 expression and established markers for liver damage. We found that the frequency of $\mathrm{Tim}-3^{+} \mathrm{CD} 4^{+}$or $\mathrm{CD} 8^{+} \mathrm{T}$ cells significantly correlated with levels of alanine aminotransferase $(\mathrm{ALT})\left(\mathrm{r}_{\mathrm{CD} 4}=0.371, \mathrm{P}_{\mathrm{CD} 4}=0.020 ; \mathrm{r}_{\mathrm{CD} 8}=0.371, \mathrm{P}_{\mathrm{CD} 8}=\right.$ $0.001)$, aspartate transaminase (AST) $\left(\mathrm{r}_{\mathrm{CD} 4}=0.496\right.$, $\left.\mathrm{P}_{\mathrm{CD} 4}=0.001 ; \mathrm{r}_{\mathrm{CD} 8}=0.618, \mathrm{P}_{\mathrm{CD} 8}<0.0001\right)$, international normalized ratio (INR) $\left(\mathrm{r}_{\mathrm{CD} 4}=0.498, \mathrm{P}_{\mathrm{CD} 4}=0.001 ; \mathrm{r}_{\mathrm{CD} 8}=\right.$ $\left.0.490, \mathrm{P}_{\mathrm{CD} 8}=0.002\right)$, and total bilirubin $\left(\mathrm{r}_{\mathrm{CD} 4}=0.610\right.$, $\left.\mathrm{P}_{\mathrm{CD} 4}<0.0001 ; \mathrm{r}_{\mathrm{CD} 8}=0.649, \mathrm{P}_{\mathrm{CD} 8}<0.0001\right)$ (Figure 2). These results suggest that Tim-3 could be used as a potential marker for assessing severity of hepatic injury in $\mathrm{CHB}$. As it was reported that Tim-3 expression was associated viral load during HIV infection, we examined whether this relationship was established in chronic HBV infection. However, we did not observe a significant correlation between serum HBV DNA with the frequency of either Tim- $3+\mathrm{CD}^{+} \mathrm{T}$ cells $\left(\mathrm{r}_{\mathrm{CD} 4}=-0.211, \mathrm{P}_{\mathrm{CD} 4}=0.204\right)$ or Tim-3+ CD8 ${ }^{+} \mathrm{T}$ cells $\left(\mathrm{r}_{\mathrm{CD} 4}=-0.206, \mathrm{P}_{\mathrm{CD} 4}=0.215\right)$.

\subsection{The frequency of Tim-3-positive $T$ cells negatively} correlates with T-bet mRNA expression in CHB patients

Tim-3 was reported to negatively regulate the Th1/Tc1 response. As T-bet was a Th1/Tc1-related transcription factor, we determined T-bet mRNA expression in PBMCs from healthy controls, AHB patients and CHB patients. The relative amount of $\mathrm{T}$-bet mRNA expression in patients was 0.89 fold of healthy controls $(\mathrm{P}=0.020)$. However, there was no significant difference between CHB (0.89 fold of healthy controls) and AHB patients (0.86 fold of healthy controls) $(\mathrm{P}=0.178)$. Lower $\mathrm{T}$-bet mRNA expression was observed in SCHB patients $(0.53$ fold of healthy controls) compared to MCHB patients
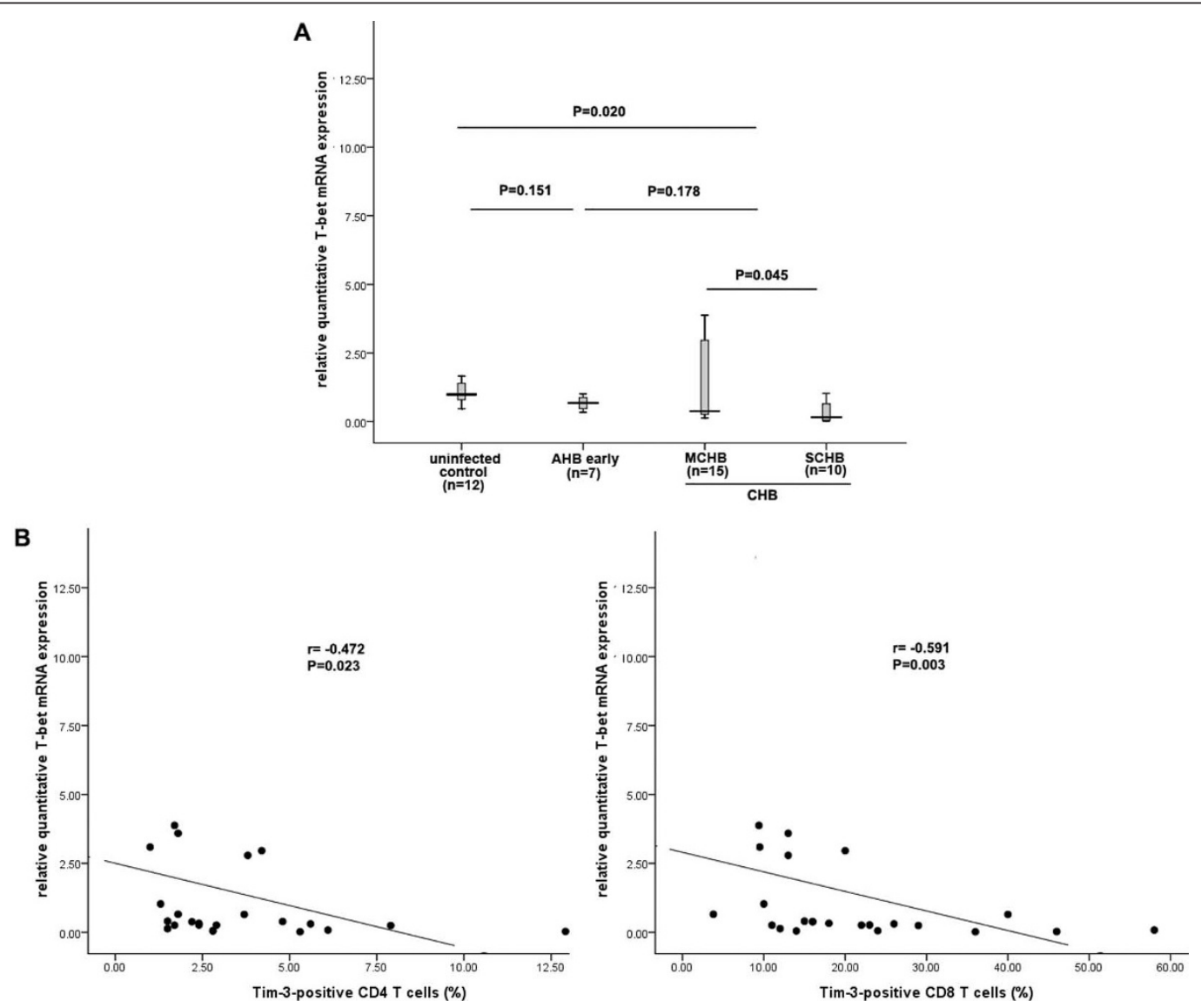

Figure 3 Association between the frequency of Tim $-3^{+} \mathrm{T}$ cells and T-bet mRNA expression in CHB patients. (A) T-bet mRNA expression was determined in patients separated into four groups: normal controls $(N=12)$, AHB patients (early phase) $(N=7)$, MCHB patients $(N=15)$ and SCHB patients $(N=10)$. The bars represent the $(95 \% \mathrm{Cl})$ T-bet mRNA expression for each group and the differences among groups were analyzed using the Mann-Whitney $U$ test. (B) Spearman correlation analysis showed a negative association between the frequency of Tim-3-postivie T cells and T-bet mRNA expression. 
(1.11 fold of health controls) $(\mathrm{P}=0.045)$ (see Figure 3A). Moreover, we observed a significant inverse correlation between T-bet mRNA expression and the frequency of Tim $-3^{+} \mathrm{T}$ cells $\left(\mathrm{r}_{\mathrm{CD} 4}=-472, \mathrm{P}_{\mathrm{CD} 4}=0.023 ; \mathrm{r}_{\mathrm{CD} 8}=-0.591\right.$, $\left.\mathrm{P}_{\mathrm{CD} 8}=0.003\right)$ (see Figure $\left.3 \mathrm{~B}\right)$. However, these correlations were not observed in AHB patients (data not shown).

\subsection{The frequency of Tim-3-positive T cells negatively} correlates with plasma IFN-gamma level in CHB patients We next assessed plasma levels of IFN-gamma, a Th1/Tc1related cytokine, in 12 uninfected controls, 7 AHB patients and $25 \mathrm{CHB}$ patients. Plasma IFN-gamma concentration were significantly lower in $\mathrm{CHB}$ patients relative to $\mathrm{AHB}$ patients and controls (INF-gamma: $28.16 \pm 34.51 \mathrm{pg} / \mathrm{ml}$ for $\mathrm{CHB}$ patients versus $78.63 \pm 79.92 \mathrm{pg} / \mathrm{ml}$ for AHB patients $[\mathrm{P}=0.045], 40.82 \pm 21.58$ for normal controls $[\mathrm{P}=0.032]$ ) (see Figure 4A). Moreover, we observed a significant inverse correlation between plasma IFN-gamma and the frequency of Tim- $3^{+} \mathrm{T}$ cells $\left(\mathrm{r}_{\mathrm{CD} 4}=-0.553, \mathrm{P}_{\mathrm{CD} 4}=0.004 ; \mathrm{r}_{\mathrm{CD} 8}=\right.$ -0.450, $\mathrm{P}_{\mathrm{CD} 8}=0.024$ ) (see Figure 4B) Again, these correlations were not observed in AHB patients (data not shown).

\subsection{Tim-3 expression was reduced in CHB patients with disease remission}

The previous results indicated a role of Tim-3 in disease progression of CHB. To further evaluate this hypothesis, we conducted a longitudinal study on Tim-3 expression on $\mathrm{T}$ cells from $8 \mathrm{CHB}$ patients before and after antiviral treatment with a 3-6 month follow-up time. All the 8 patients achieved complete biochemical (ALT normalization) and virological response (suppression of serum HBV DNA to undetectable levels) after 6-months of antiviral treatment. As shown in Figure 5A, Tim-3 expression on both $\mathrm{CD}^{+}$and $\mathrm{CD}^{+} \mathrm{T}$ cells was significantly reduced in these patients (CD4: $2.96 \pm 1.85 \%$ for early phase versus $1.11 \pm 0.36 \%$ for convalescence phase, $\mathrm{P}=0.028$; CD8: $(17.20 \pm 5.89 \%$ for early phase versus $5.90 \pm 2.54 \%$ for convalescence phase, $\mathrm{P}=0.001)$ ).

\subsection{Tim-3 expression was reduced in AHB patients at convalescence stage}

We also performed follow-up of 6 AHB patients to analyze the dynamic alteration of Tim-3 expression with
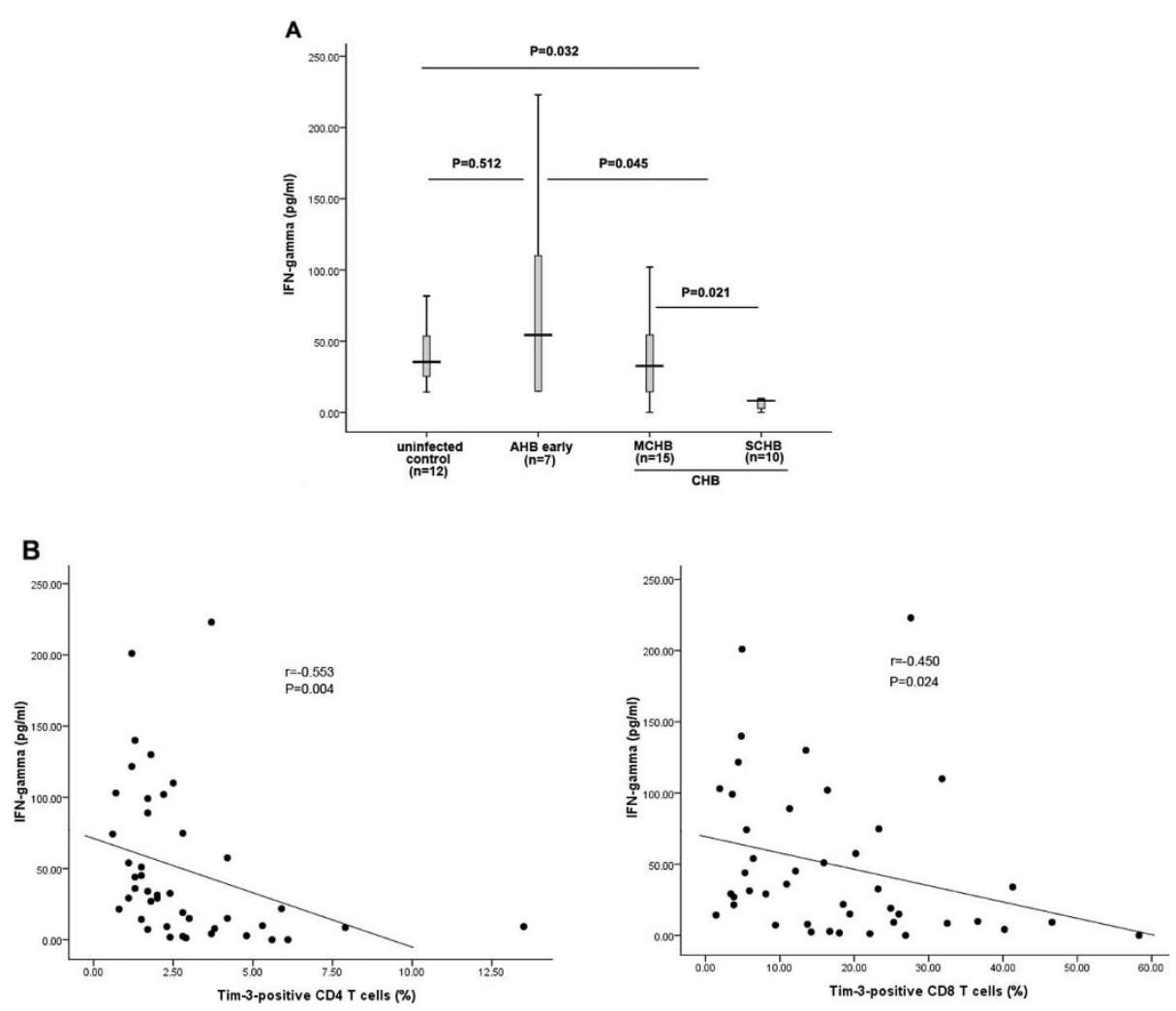

Figure 4 Association between the frequency of Tim- $3^{+}$T cells and plasma IFN-gamma level in CHB patients. (A) IFN-gamma was measured in plasma from normal controls $(N=12)$, AHB patients (early phase) $(N=7)$, MCHB patients $(N=15)$ and SCHB patients $(N=10)$. The bars represent the $(95 \% \mathrm{CI})$ IFN-gamma level for each group and the differences among groups were analyzed using the Mann-Whitney $U$ test. (B) Spearman correlation analysis showed there were negative associations between the frequency of Tim-3-postivie T cells and plasma IFNgamma level. 
disease convalescence. AHB convalescence was defined as ALT normalization and HBsAg-seroconversion. As shown in Figure $5 \mathrm{~B}$, the $\mathrm{Tim}-3^{+} \mathrm{CD} 8^{+} \mathrm{T}$ cell frequency of the AHB patients was high in the early acute phase and significantly reduced in the convalescent phase $(25.27 \pm 1.85 \%$ for early phase versus $3.98 \pm 1.62 \%$ for convalescence phase, $\mathrm{P}<0.0001$ ). Tim-3 expression on $\mathrm{CD} 4^{+} \mathrm{T}$ cells also appeared to be reduced although this effect did not quite achieve statistical significance (3.97 $\pm 2.14 \%$ for early phase versus $1.93 \pm 1.18 \%$ for convalescence phase, $\mathrm{P}=0.081$ ).

\section{Discussion}

Tim-3, expressed in both innate and adaptive immune cells, plays a pivotal role in immune regulation and immune tolerance [17]. A recent study showed that HBV infection can up-regulate Tim-3 expression in NK cells, which may in turn suppress NK-cell functions in $\mathrm{CHB}$ patients [18]. Viral clearance and liver damage is thought to be mediated primarily through $\mathrm{T}$ cellmediated responses [19], however; up to now, no study investigated the role of Tim-3 in regulating $\mathrm{T}$-cell immunity in $\mathrm{CHB}$ patients. In this study, we determined the expression profile of Tim-3 on peripheral T cell subsets from $\mathrm{CHB}$ and $\mathrm{AHB}$ patients and investigated the potential role of Tim-3 in disease progression.

We first demonstrated increased Tim-3 expression on $\mathrm{CD}^{+}$and $\mathrm{CD}^{+}{ }^{+}$cells in patients with $\mathrm{CHB}$ and found that Tim-3 expression was further enhanced in samples from patients with more severe stages of CHB. Moreover, there was a significant positive correlation between Tim-3 expression with conventional markers for hepatic injury such as ALT, AST, INR and TB. These results indicate that Tim-3 expression level is related to the degree of liver inflammation. This was further supported by an observed decrease of Tim-3 expression in CHB patients with disease resolution. Since activated T cells cause liver injury, and the severity of liver inflammation
A

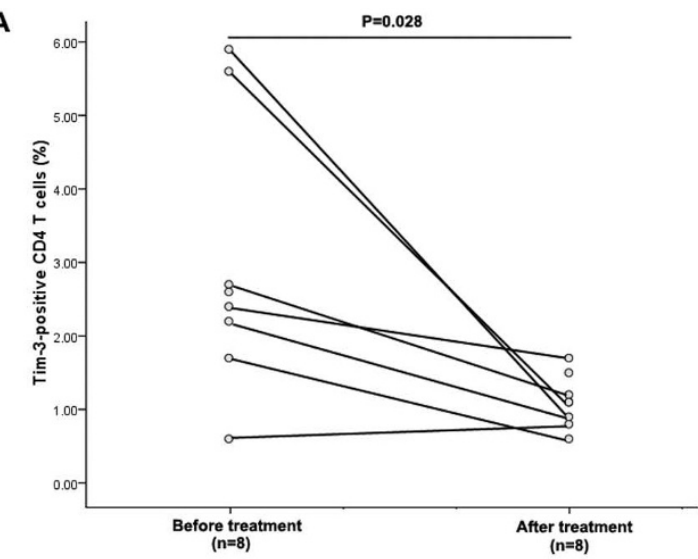

B

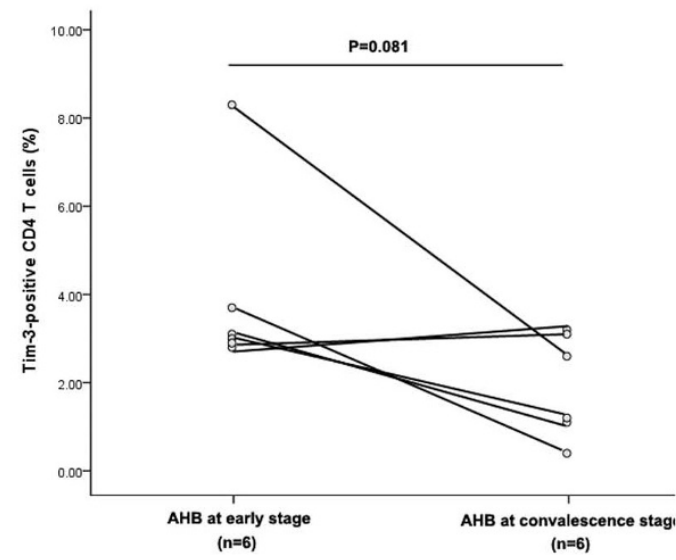

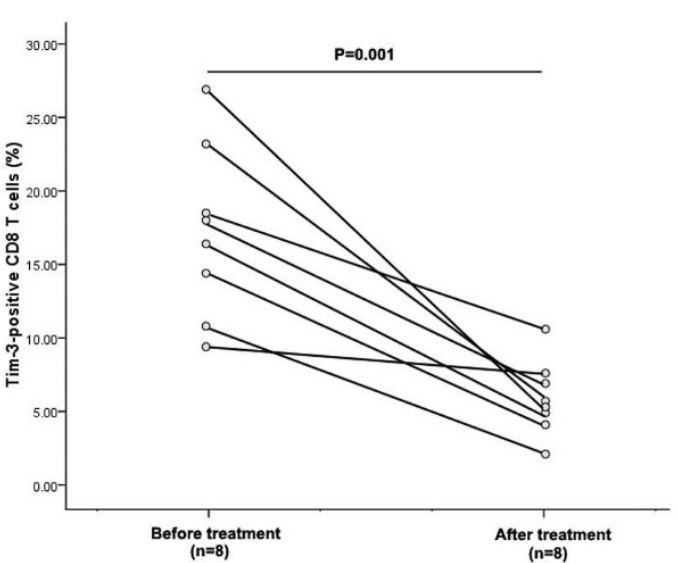

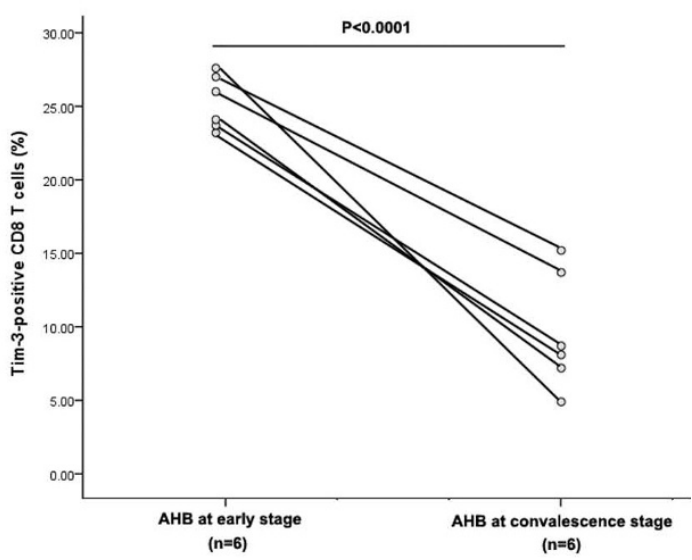

Figure 5 longitudinal analysis of Tim-3 expression in CHB and AHB patients. (A) The percentage of Tim- $3^{+} T$ cells decreased in $\mathrm{CHB}$ patients after successful antiviral treatment. The frequency of Tim $-3^{+}$cells in $\mathrm{CD} 4^{+}$and $\mathrm{CD} 8^{+} \mathrm{T}$ cells before and after treatment is shown. (B) The frequency of Tim- $3^{+} \mathrm{T}$ cells decreased in AHB patients during disease convalescence. The frequency of Tim- $3^{+}$cells in $\mathrm{CD} 4^{+}$and $\mathrm{CD} 8^{+} \mathrm{T}$ cells at early stage and convalescence stage is shown. 
is correlated with the number of intra-hepatic activated $\mathrm{T}$ cells [19], up-regulation of Tim-3 expression might be due to the activation of $\mathrm{T}$ cells.

Accumulating evidence indicates that Tim-3 could negatively regulate adaptive immune response. Upon interaction with its ligand, Galectin-9, Tim-3 induces Th1 cell death and suppresses IFN-gamma production [10]. Further, IFN- $\gamma$ secretion from $\mathrm{CD}^{+}$and $\mathrm{CD} 8^{+} \mathrm{T}$ cells could be restored by blockade of the Tim-3/Galectin-9 pathway or by Tim-3 knockdown using specific shRNAs [11]. In this study, we demonstrated lower expression of T-bet mRNA and lower levels of plasma IFN-gamma in $\mathrm{CHB}$ patients compared with $\mathrm{AHB}$ patients or uninfected controls, suggesting an impaired Th1/Tc1 response in CHB patients. We further found an inverse correlation between Tim-3 expression and both T-bet expression and plasma IFN-gamma, in CHB patients but not AHB patients. These results provided suggestive evidence that Tim-3 down-regulates the Th1/ Tc1 response, which might contribute to viral persistence during chronic HBV infection.

Previous work showed that Tim-3 was highly expressed on $\mathrm{CD} 4^{+}$and $\mathrm{CD} 8^{+} \mathrm{T}$ cells in acutely/early HIV infected individuals ${ }^{11}$. Similarly, we also observed high expression of Tim-3 on T cells during the early stage of acute HBV infection. However, in AHB patients, Tim-3 was expressed as a transient up-regulation, which subsequently decreased at convalescence stage. This Tim-3 expression pattern was in line with that of PD-1 observed during acute-limited HBV infection [20]. Tim3 expression was not associated with severity of hepatic injury in AHB patients. Furthermore, unlike $\mathrm{CHB}$, there was no association between Tim-3 expression and IFNgamma or TNF-alpha level in AHB patients. Overall, these results suggested a different role of Tim-3 in the pathogenesis of $\mathrm{AHB}$ and $\mathrm{CHB}$, which might determine the diversification of HBV infection.

\section{Conclusions}

Collectively, the expression of Tim-3 is up-regulated on circulating $\mathrm{CD} 4^{+}$and $\mathrm{CD} 8^{+} \mathrm{T}$ cells in $\mathrm{CHB}$ patients. Tim-3 was highly expressed on $\mathrm{T}$ cells from AHB patients as well, however, its expression decreased dynamically in convalescence phase. Tim-3 expression positively correlated with disease severity and negatively correlated with Th1/Tc1 response in CHB patients. Our data suggest that Tim-3 might be a potential marker for evaluating severity of hepatic flare-up. However, further studies were needed to clarify the exact role of Tim-3 in the pathogenesis of CHB.

\section{List of abbreviations}

(Tim-3): T-cell immunoglobulin domain and mucin domain-containing molecule-3; $(\mathrm{CHB})$ : chronic hepatitis $\mathrm{B}$; $(\mathrm{MCHB})$ : moderate chronic hepatitis $\mathrm{B}$;
(SCHB): severe chronic hepatitis $B$; $(A H B)$ : acute hepatitis $B$; $(A L T)$ : alanine aminotransferase; (AST): aspartate transaminase; (TB): total bilirubin; (INR): international normalized ratio; (INF-gamma): interferon-gamma.

\section{Acknowledgements}

The work was supported by The Major national S\&T Projects for infectious diseases (11th Five Year) (2008ZX10002-007) and The National Natural Science Fund (81071767). We declared no conflicts of interest.

\section{Authors' contributions}

WW, SY, CF, CZ and ZM designed the study. WW, SY and $L J$ participated in conducting experiments. WW, SY, CF and ZM performed statistical analysis and data interpretation. WW, SY and $L J$ wrote the main body of the article under the supervision CF, CZ and. ZM. All authors have read and approved the final manuscript.

\section{Competing interests}

No benefits in any form have been received or will be received from a commercial party related directly or indirectly to the subject of this article.

Received: 6 December 2010 Accepted: 11 March 2011

Published: 11 March 2011

\section{References}

1. Lok ASF, McMahon BJ: Chronic hepatitis B: Update 2009. Hepatology 2009, 50:661-662.

2. Rehermann B, Fowler P, Sidney J, Person J, Redeker A, Brown M, Moss B, Sette A, Chisari FV: The cytotoxic T lymphocyte response to multiple hepatitis $B$ virus polymerase epitopes during and after acute viral hepatitis. J Exp Med 1995, 181:1047-58.

3. Chisari FV, Isogawa M, Wieland SF: Pathogenesis of hepatitis B virus infection. Pathol Biol (Paris) 2010, 58:258-66.

4. Barber DL, Wherry EJ, Masopust D, Zhu B, Allison JP, Sharpe AH, Freeman GJ, Ahmed R: Restoring function in exhausted CD8 T cells during chronic viral infection. Nature 2006, 439:682-7.

5. Day CL, Kaufmann DE, Kiepiela P, Brown JA, Moodley ES, Reddy S, Mackey EW, Miller JD, Leslie AJ, DePierres C, Mncube Z, Duraiswamy J, Zhu B, Eichbaum Q, Altfeld M, Wherry EJ, Coovadia HM, Goulder PJ, Klenerman P, Ahmed R, Freeman GJ, Walker BD: PD-1 expression on HIVspecific T cells is associated with T-cell exhaustion and disease progression. Nature 2006, 443:350-4.

6. Golden-Mason L, Palmer B, Klarquist J, Mengshol JA, Castelblanco N, Rosen HR: Upregulation of PD-1 expression on circulating and intrahepatic hepatitis $C$ virus-specific CD8+ T cells associated with reversible immune dysfunction. J Virol 2007, 81:9249-58.

7. Boni C, Fisicaro P, Valdatta C, Amadei B, Di Vincenzo P, Giuberti T, Laccabue D, Zerbini A, Cavalli A, Missale G, Bertoletti A, Ferrari C: Characterization of hepatitis B virus (HBV)-specific T-cell dysfunction in chronic HBV infection. J Virol 2007, 81:4215-25.

8. Crawford A, Wherry EJ: The diversity of costimulatory and inhibitory receptor pathways and the regulation of antiviral T cell responses. Curr Opin Immunol 2009, 21:179-86.

9. Sabatos CA, Chakravarti S, Cha E, Schubart A, Sanchez-Fueyo A, Zheng XX, Coyle AJ, Strom TB, Freeman GJ, Kuchroo VK: Interaction of Tim-3 and Tim-3 ligand regulates $T$ helper type 1 responses and induction of peripheral tolerance. Nat Immunol 2003, 4:1102-10.

10. Zhu C, Anderson AC, Schubart A, Xiong H, Imitola J, Khoury SJ, Zheng XX, Strom TB, Kuchroo VK: The Tim-3 ligand galectin-9 negatively regulates $T$ helper type 1 immunity. Nat Immunol 2005, 6:1245-52.

11. Jones RB, Ndhlovu LC, Barbour JD, Sheth PM, Jha AR, Long BR, Wong JC, Satkunarajah M, Schweneker M, Chapman JM, Gyenes G, Vali B, Hyrcza MD, Yue FY, Kovacs C, Sassi A, Loutfy M, Halpenny R, Persad D, Spotts G, Hecht FM, Chun TW, McCune JM, Kaul R, Rini JM, Nixon DF, Ostrowski MA: Tim-3 expression defines a novel population of dysfunctional T cells with highly elevated frequencies in progressive HIV-1 infection. J Exp Med 2008, 205:2763-79.

12. Golden-Mason L, Palmer BE, Kassam N, Townshend-Bulson L, Livingston S, McMahon BJ, Castelblanco N, Kuchroo V, Gretch DR, Rosen HR: Negative immune regulator Tim-3 is overexpressed on T cells in hepatitis $C$ virus infection and its blockade rescues dysfunctional CD4+ and CD8+ T cells. J Virol 2009, 83:9122-30. 
13. Jin $H T$, Anderson $A C$, Tan WG, West EE, Ha SJ, Araki K, Freeman GJ, Kuchroo VK, Ahmed R: Cooperation of Tim-3 and PD-1 in CD8 T-cell exhaustion during chronic viral infection. Proc Natl Acad Sci USA 2010, 107:14733-8.

14. Xu D, Fu J, Jin L, Zhang H, Zhou C, Zou Z, Zhao JM, Zhang B, Shi M, Ding $X$, Tang $Z$, Fu YX, Wang FS: Circulating and liver resident CD4+CD25 + regulatory $T$ cells actively influence the antiviral immune response and disease progression in patients with hepatitis B. J Immunol 2006, 177:739-47.

15. Jung MC, Spengler U, Schraut W, Hoffmann R, Zachoval R, Eisenburg J, Eichenlaub D, Riethmuller G, Paumgartner G, Ziegler-Heitbrock HW, et al: Hepatitis B virus antigen-specific T-cell activation in patients with acute and chronic hepatitis B. J Hepatol 1991, 13:310-7.

16. Wu W, Li J, Chen F, Zhu H, Peng G, Chen Z: Circulating Th17 cells frequency is associated with the disease progression in HBV infected patients. I Gastroenterol Hepatol 2010, 25:750-7.

17. Rodriguez-Manzanet R, DeKruyff R, Kuchroo VK, Umetsu DT: The costimulatory role of TIM molecules. Immunol Rev 2009, 229:259-70.

18. Ju Y, Hou N, Meng J, Wang X, Zhang X, Zhao D, Liu Y, Zhu F, Zhang L, Sun W, Liang X, Gao L, Ma C: T cell immunoglobulin- and mucin-domaincontaining molecule-3 (Tim-3) mediates natural killer cell suppression in chronic hepatitis B. J Hepatol 2010, 52:322-9.

19. Maini MK, Boni C, Lee CK, Larrubia JR, Reignat S, Ogg GS, King AS, Herberg J, Gilson R, Alisa A, Williams R, Vergani D, Naoumov NV, Ferrari C, Bertoletti A: The role of virus-specific CD8(+) cells in liver damage and viral control during persistent hepatitis B virus infection. J Exp Med 2000, 191:1269-80.

20. Zhang Z, Jin B, Zhang JY, Xu B, Wang H, Shi M, Wherry EJ, Lau GK, Wang FS: Dynamic decrease in PD-1 expression correlates with HBVspecific memory CD8 T-cell development in acute self-limited hepatitis B patients. J Hepatol 2009, 50:1163-73.

doi:10.1186/1743-422X-8-113

Cite this article as: Wu et al:: Tim-3 expression on peripheral T cell subsets correlates with disease progression in hepatitis B infection. Virology Journal 2011 8:113.

\section{Submit your next manuscript to BioMed Central and take full advantage of:}

- Convenient online submission

- Thorough peer review

- No space constraints or color figure charges

- Immediate publication on acceptance

- Inclusion in PubMed, CAS, Scopus and Google Scholar

- Research which is freely available for redistribution

Submit your manuscript at www.biomedcentral.com/submit
Biomed Central 